Kohl: a Journal for Body and Gender Research

Vol. 6, No. 3 (Winter 2020)

\title{
Transitional Stills
}

Theo Louk 


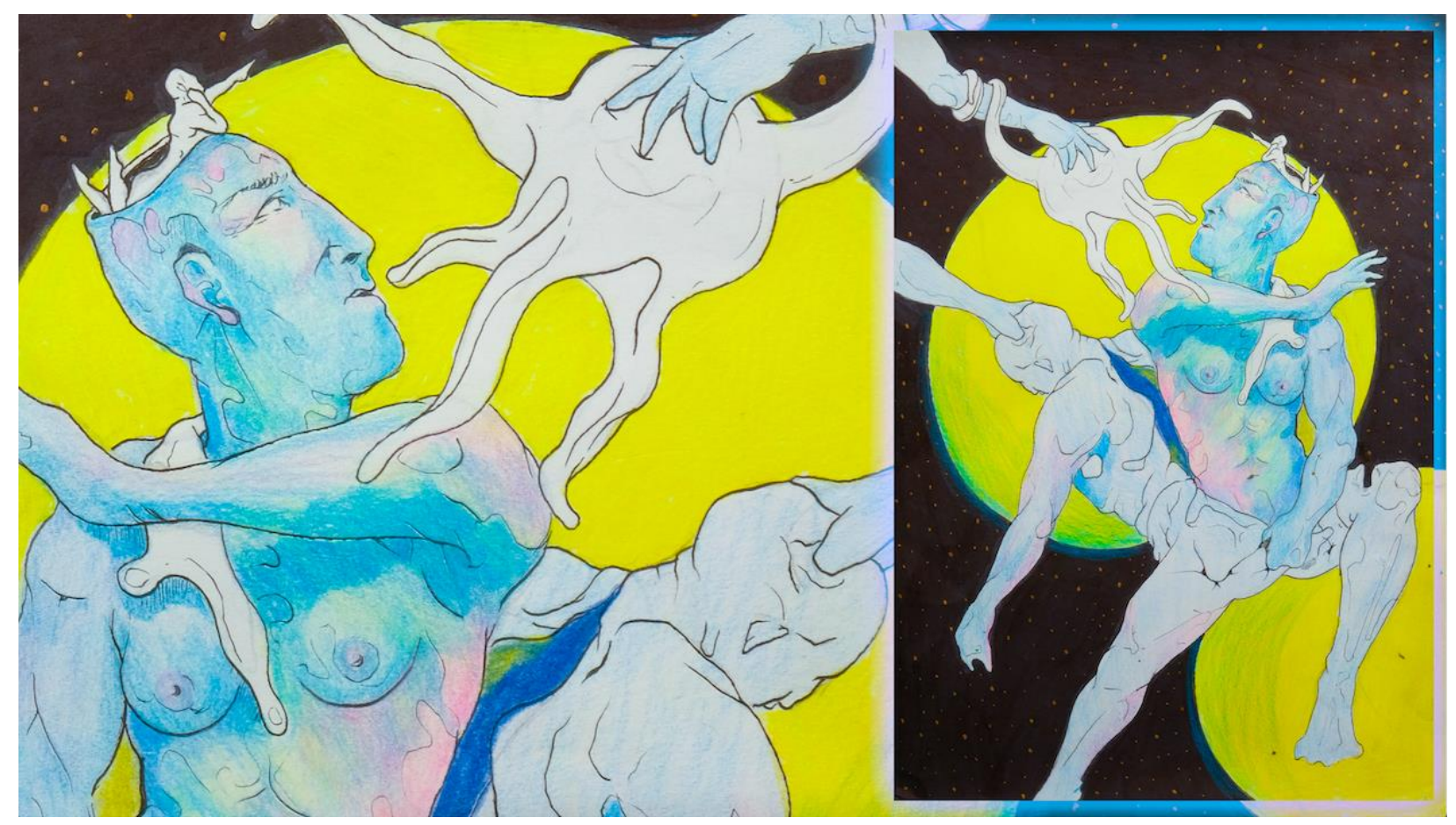

Depicting bodies of emotion and numbness, physical and mental transition, landscapes of distant spaces, and lovers who have lost their identity. Even if there is no narrative I consciously follow, I guess it mostly ends in searching the mellow in the monstrous, the connection between contradictions, the missing elements that unify what seems separated, and the sacred in the prohibited.

Queerness in my eyes, wanted or unwanted, seems like a state of being that liquefies anything that has become solid and stiff, repressive and dangerous. There is all of this strength that lies in the most vulnerable moments that we are able to share with each other. And in this vulnerability there lies hurt, wonder, ugliness and solitude and connection that is most beautifully expressed when it is being met by love and courage.

To hold space for each other and to be there for each other, as for ourselves, is something I believe in. The pictures I draw tell of conflict, faith, trans-identity, madness, death, and "queer love," with the conclusion that you can't bargain with demons for peace.

Thank you Safa, Ghiwa, and Kohl for having me here $<3$ 
Transitional Stills

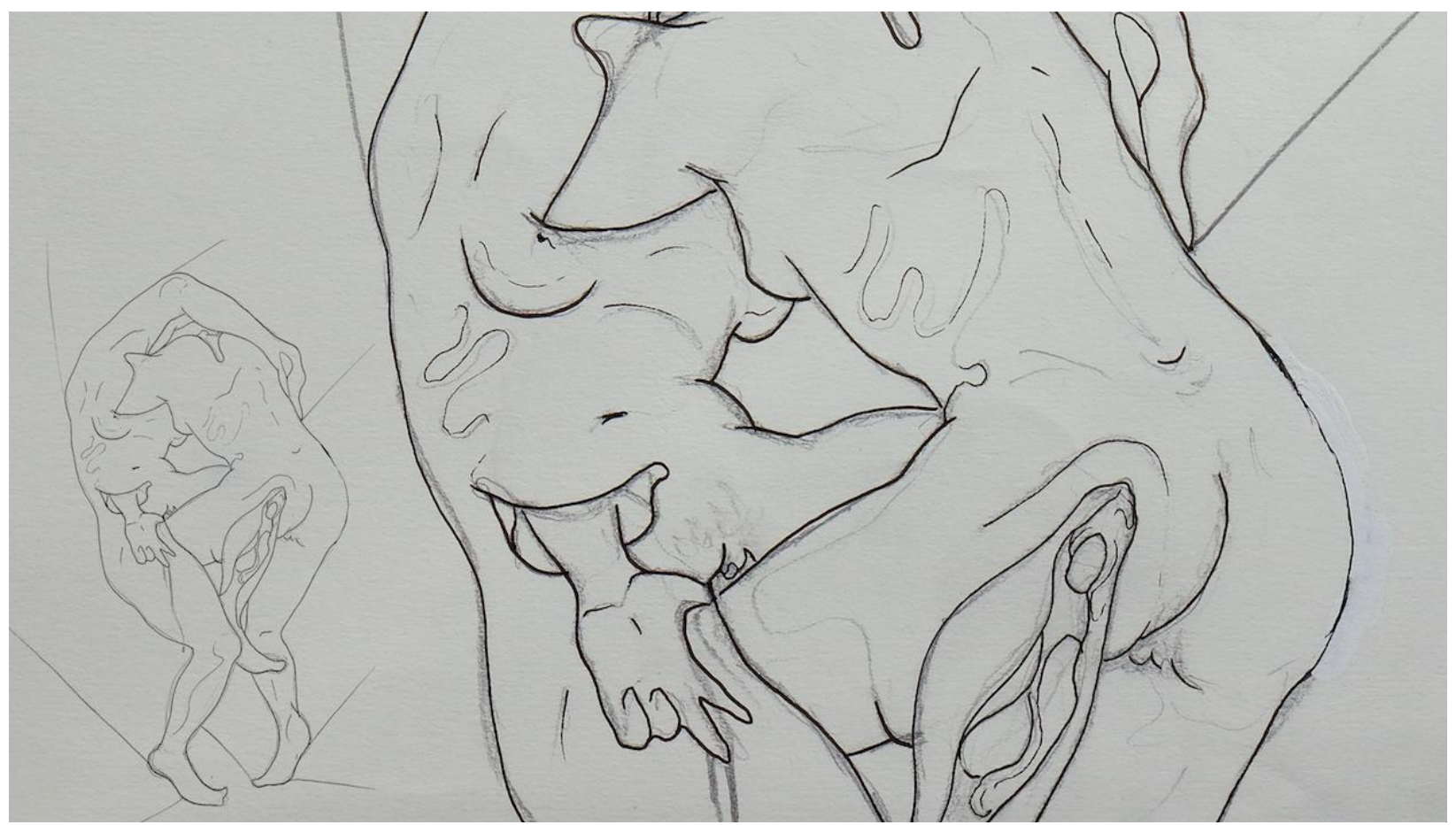

1 melting lovers
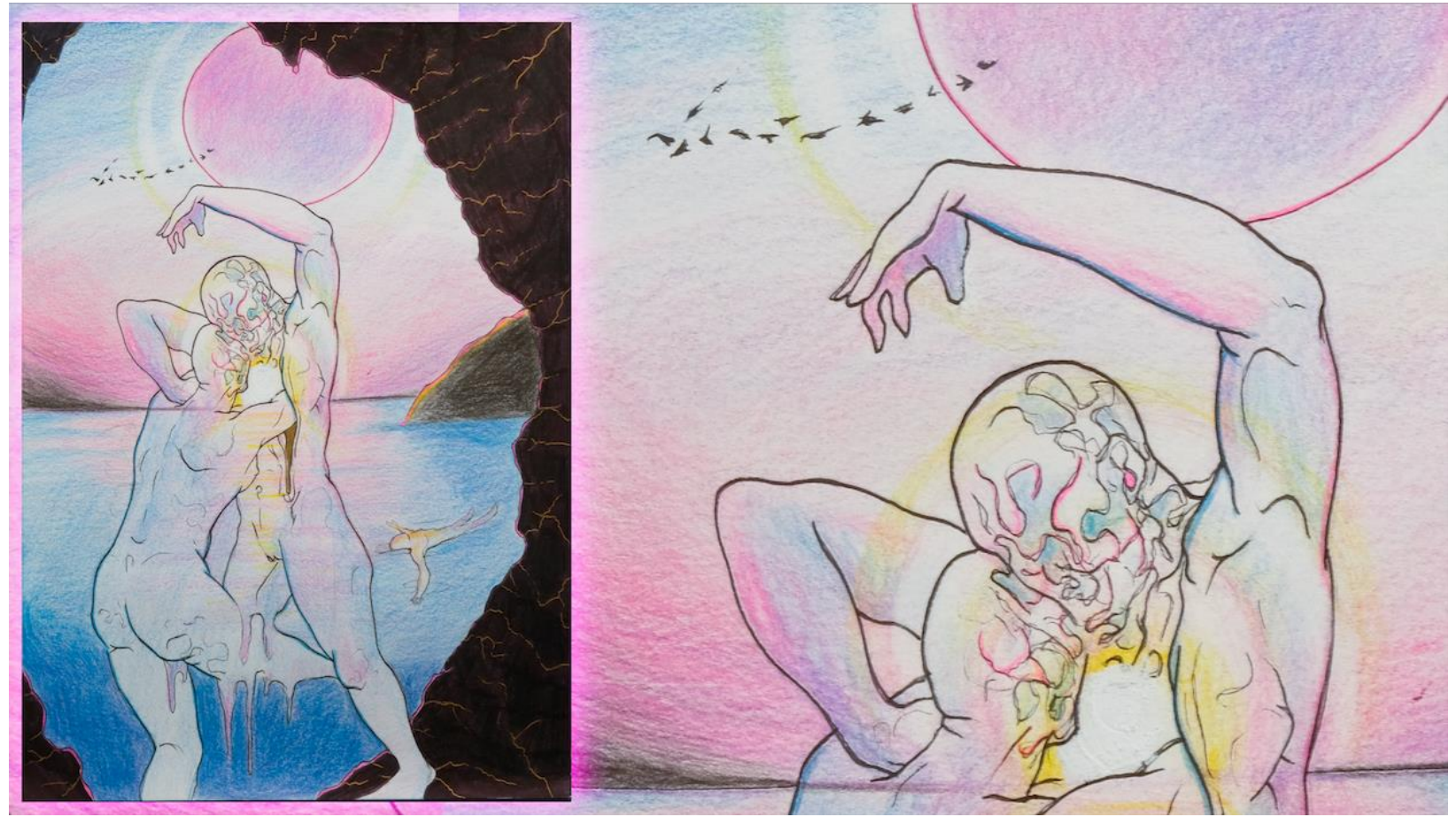

2 Battle in the cave 
Kohl 6.3

350

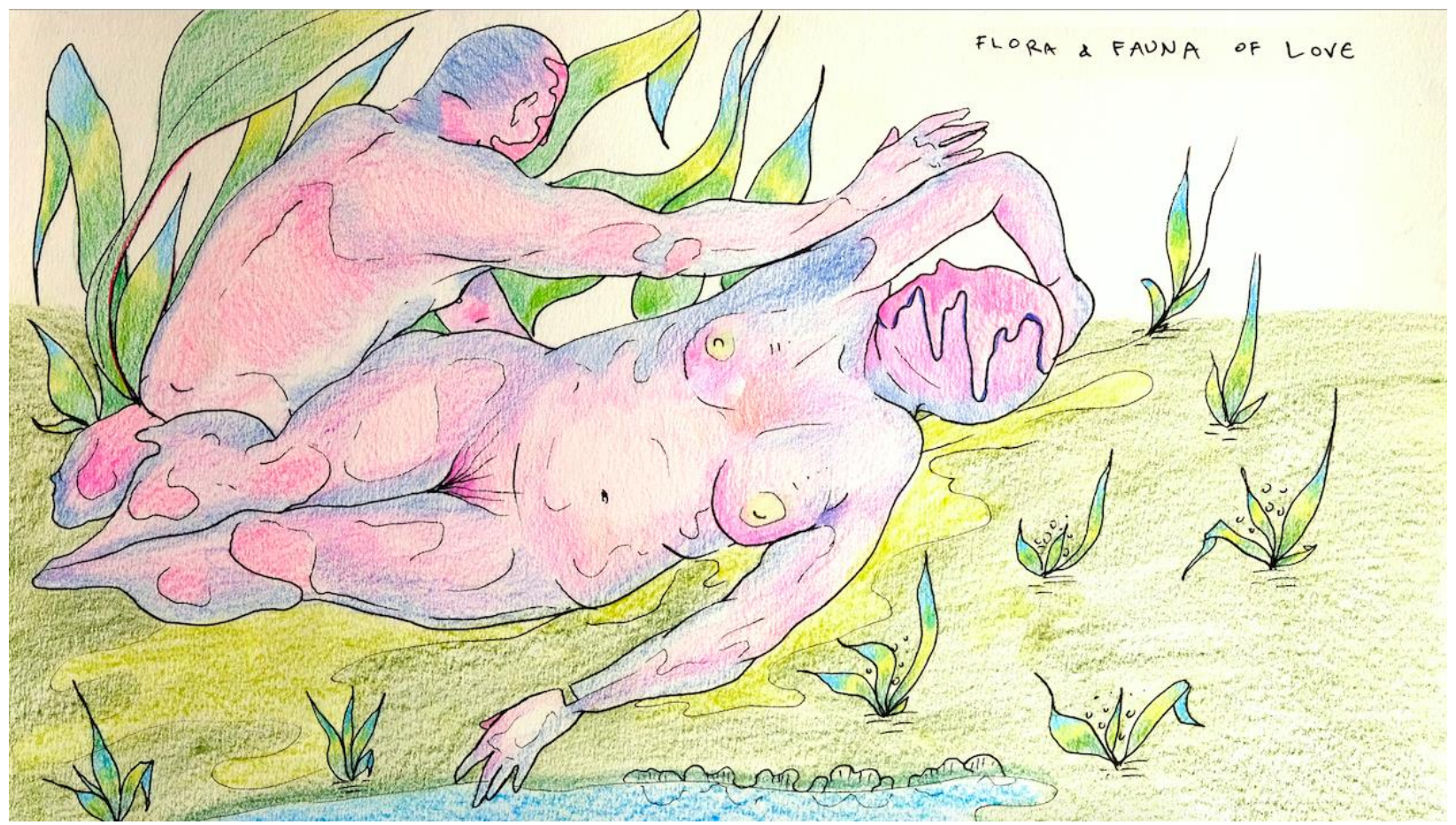

3 my friend $M$. with the love she deserves resting by the pond 